\title{
Autopsy Unveiled the Mystery of Death of an Elderly Female Due to Minor Degree Burn Injury
}

Bandyopadhyay $\mathrm{C}^{1 *}$, Sujash Biswas ${ }^{1}$, Sayan Biswas ${ }^{2}$, Roy $\mathrm{S}^{2}$, Sukul B ${ }^{3}$

${ }^{1}$ Assistant Professor, Upgraded Department of Forensic and State Medicine, MCH, Kolkata, India.

${ }^{2}$ PGT, Upgraded Department of Forensic and State Medicine, MCH, Kolkata, India.

${ }^{3}$ Professor and Head, Upgraded Department of Forensic and State Medicine, MCH, Kolkata, India.

\begin{abstract}
The modern era of urbanization has seen a growing number of burn injuries inflicted in diverse manners. According to the National crime Research Bureau (NCRB) report of 2002 over 30,000 people died in India due to burn injuries, thereby contributing $9 \%$ of the total deaths. In all these conspicuous cases of deaths due to burn injuries, we, the autopsy surgeons, perform the complete autopsy to arrive at the conclusion regarding cause of death and also to help the investigating agencies to deduce the opinion regarding manner of the particular death. But the matter gets complicated medicolegally and more interesting academically if another overt pathological finding is detected incidentally during the course of dissection. In this following case one old lady was presented to us with minor degree ante mortem burn injuries. But after meticulous post mortem examination, huge hemopericardium with evidence of ante-mortem myocardial rupture was revealed, which single handedly can cause death.
\end{abstract}

Keywords: Burn Injuries; Hemopericardium; Myocardial Rupture; Autopsy.

\section{*Corresponding Author:}

Dr. Chandan Bandyopadhyay,

$3^{\text {rd }}$ Lane, Farm Side Road, PO-Chinsurah (RS), Dt- Hooghly, West Bengal, 712102, India.

E-mail: banerjee.chandan09@gmail.com

Recieved: February 22, 2015

Accepted: April 14, 2015

Published: April 16, 2015

Citation: Bandyopadhyay C, et al., (2015) Autopsy Unveiled the Mystery of Death of an Elderly Female Due to Minor Degree Burn Injury. Int J Forensic Sci Pathol. 3(4), 110-112. doi: http://dx.doi.org/10.19070/2332287X-1500026

Copyright: Bandyopadhyay $\mathbf{C}^{\circ}$ 2015. This is an open-access article distributed under the terms of the Creative Commons Attribution License, which permits unrestricted use, distribution and reproduction in any medium, provided the original author and source are credited.

\section{Introduction}

According to the Wallace Rule of Nine, for adults, $50 \%$ of body surface area if gets burnt can be fatal for a person. However the relationship between the extent of surface area burnt and the degree of morbidity and also mortality is very complex; both from clinical and pathological points of view. In case of burn injury the most common cause of death within 48 hrs. is hypovolemic shock. In most of the cases of burn injury there is an evidence of violent struggle of the victim to get rid of the pain and agony resulting in a sudden surge in catecholamines i.e. Epinephrine and Norepinephrine. Also there is sudden spurt of $\mathrm{K}+$ followed by massive fall. All these can play a massive role in worsening of the condition of an already weakened heart and can precipitate a condition like acute myocardial infarction or rupture of thinned out and fibrosed myocardial wall. Now, for this case, advanced age played a well-recognized risk factor for adverse cardiovascular events. A substantial body of literature, some of is cited within the scope of this article, demonstrates increased cardiovascular morbidity and mortality in geriatric trauma patients compared to their younger counterparts.

\section{Case History}

On one December afternoon a 65 year old lady was rushed to the Medical College and Hospital, Kolkata as she received burn injury and there was no preceding history of foul play as per police inquest. But even after receiving medical attention she succumbed to death a day after the admission. The body was then sent to Kolkata Police Morgue for autopsy.

\section{External Examination}

1) One dermo-epidermal burn injury measuring 12 inches in length and 6 inches in width horizontally distributed over an area comprising of right hypochondrium and right lumber region.

Figure 1. Dermoepidermal burn over right abdominal region.

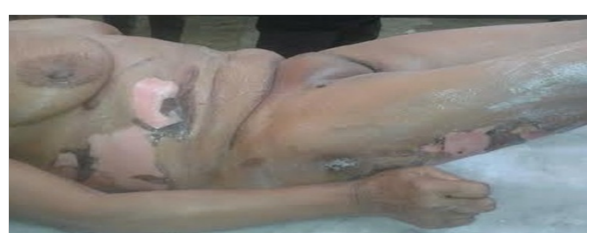


2) One dermo-epidermal burn injury measuring 13 inches in length and 7.5 inches in width, distributed over both the gluteal regions, encroaching the adjacent parts of posterior surfaces of both the thighs and sacral region of the back.

Figure 2. Burn over the gluteal regions.

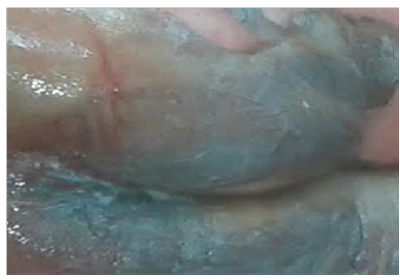

\section{Internal Examination}

On dissection, all the internal organs were found to be congested but the most characteristic finding which was revealed to us after dissection was that of the pericardial sac and the heart.

The pericardial sac was filled with 150 grams of clotted blood

Figure 3. Clotted blood after opening the pericardium.

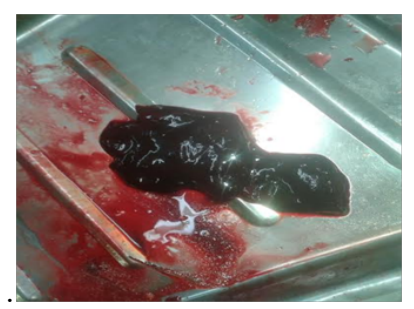

In the heart, extravasation of blood, measuring 3 inches in length and 2 inches in breadth, was noted in an area surrounding the apical region and comprising of both the ventricles.

Figure 4. Apical contusion in the Heart.

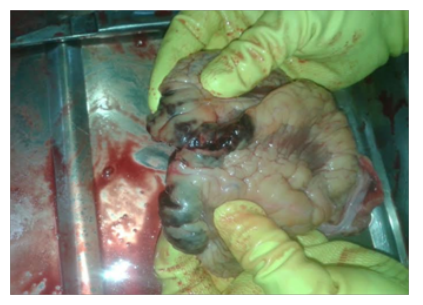

After opening the heart there was evidence of full thickness myocardial rupture.

Figure 5. Myocardial rupture.

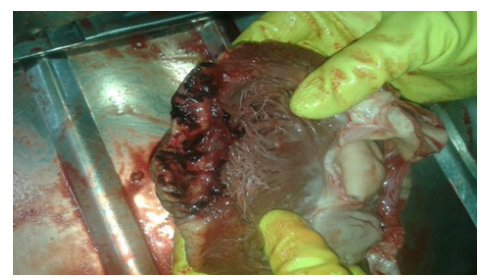

\section{Discussion}

Burns are among the most devastating injuries encountered in Medicine and are a leading cause of life-threatening trauma worldwide. According to the Centers for Disease Control and Prevention, someone in the United States dies in a fire every 175 minutes and is injured every 31 minutes. Groups with an increased risk for fire-related injury and death include children under 5 and adults more than 65 years of age [1]. In acute burn injury within minutes to hours of injury, burned tissues release inflammatory and vasoactive mediators including histamine, prostaglandins, kinins, thromboxane, and nitric oxide that increase capillary permeability and cause localized burn wound edema [1, 2]. In addition to the local effects of burn injury, major burns cause the release of circulating mediators such as tumor necrosis factor and interleukins that result in a systemic inflammatory response syndrome within 6 to 8 hours of injury. The hyper metabolic response to burns is more severe and sustained than any other form of trauma. A massive surge in catecholamines and corticosteroids, 10 to 50 times greater than unburned plasma levels, drives the hyper metabolic response [1].

The estimation of the surface area of the body involved is usually worked out by the Rule of Nine (Wallace); palmar surface of the patient's hand being one percent of total body surface area (TBSA). According to American Burn association, Minor burn injury comprises of $<10 \%$ TBSA burn in adults, Moderate burn is $10 \%-20 \%$ TBSA burn in adults whereas Major burn Criteria is $>20 \%$ TBSA burn in adults $[3,4]$. The prognosis is influenced by the age of the patient, his/her physical health at the time of the injury and also the treatment given. Under good treatment young children may recover from second degree burns involving 50-60 percent of their total body surface area. At 40 years recovery from burns involving over 40 percent of the total body surface area is unlikely and in old age burn involving even 10 percent of the total body surface area are likely to prove fatal [5]. As mentioned above, surge in the epinephrine and norepinephrine and also the sudden spurt of $\mathrm{K}+$ followed by sudden fall may sensitize the heart in the "Post Exercise Peril" Period leasing to increased oxygen demand and massive tachycardia [6]. All these incidents may collectively aggravate a previously weakened heart or can dissect through a fibrosed area of an old healed infarct in the myocardium resulting in rupture of the free infarct wall of the myocardium [7].

A minimum amount of $100 \mathrm{ml}$ blood in the pericardium in case of an adult is sufficient to act as an imminent danger to life [8]. If bleeding continues intra pericardial pressure rises, compressing both ventricles during diastole. Ventricular filling is thus impaired and the stroke volume or the blood ejected from both sides of heart is proportionately reduced. The hemodynamic result is referred to as Cardiac Tamponade and is manifested by low cardiac output, arterial hypotension (shock) and venous hypertension [9]. Since in most elderly people, Ischemic Heart disease is an incidental finding, post-infarction rupture followed by postmortem revelation of hemopercardium is not a rare finding among autopsy surgeons and also has been mentioned in various literatures $[10,11]$.

\section{Conclusion}

Cardiovascular heart disease represents the leading cause of death in both men and women older than 65 years. The prevalence and the severity of atherosclerotic coronary artery disease (CAD) increase with age in both men and women. Autopsy studies have shown that more than $50 \%$ of the people older than 60 years have significant CAD, with increasing prevalence of left main and/or 
triple-vessel CAD with older age. Subclinical vascular disease, i.e. abnormal echocardiograms, increased carotid intima-media thickness or an abnormal ankle brachial index is common in elderly people with electrocardiographic (ECG) evidence of myocardial infarction (MI). In the Cardiovascular Health Study, such abnormalities were detected in 22 percent of women and 33 percent of men aged 65 to 70 years and 43 percent of women and 45 percent of men older than 85 years. As mentioned above in acute burn injury an undiagnosed old infarct may rupture through its free infarct wall giving rise to a massive hemopercardium which can be easily regarded as a major contributing factor in an elderly lady even with minor burn injury.

\section{References}

[1]. Kimmy R, Harvin. Anaesthetic management of patients with major burn injury, ANA journal, 80: 6 .

[2]. Reddy K.S. Narayan, Essentials of Forensic Medicine and Toxicology, (32nd edtn), chapter 11.

[3]. (2010) American Burn Association, National Burn Repository IL: American
Burn Association National Burn Repository Advisory Committee, Chicago.

[4]. (2011) American Burn Association Website. Burn Incidence and Treatment in the United States 6:5 www.ameriburn.org.

[5]. Camps FE (1968) Gardwohl's Legal Medicine. (2nd edtn), John Wright and sons Limited, Bristol 379.

[6]. Maio, Vincent J (2001) Forensic Pathology, chapter 22, Sudden death after violent struggle.

[7]. Chang HW, Wang CP, Cheng CI, Chua S, Chen MC (2003) Cardiac rupture complicating acute myocardial infarction in the direct percutaneous coronary intervention reperfusion era. Chest 124: 565-71.

[8]. Fauci Anthony, Localzo Joseph (2008) Harrisons Principal of Internal medicine, (17thedtn) New Jersey 193-200.

[9]. Tedeschi CG, Eckert WG, Tedeschi LG (1977) Forensic Medicine, WB Saunders Company, Philadelphia: 1.

[10]. Reddy SG, Roberts WC (1989) Frequency of rupture of the left ventricular free wall or ventricular septum among necropsy cases of fatal acute myocardial infarction since introduction of coronary care units. Am J Cardiol; 63(13): 906-11.

[11]. Raitt MH, Kraft CD, Gardner CJ, Pearlman AS, Otto CM (1993) Subacute ventricular free wall rupture complicating myocardial infarction. Am Heart J 126(4): 946-55. 